International Journal of Current Advanced Research

ISSN: O: 2319-6475, ISSN: P: 2319 - 6505, Impact Factor: SJIF: 5.995

Available Online at www.journalijcar.org

Volume 6; Issue 3; March 2017; Page No. 3110-3113

DOI: http://dx.doi.org/10.24327/ijcar.2017.3113.0196

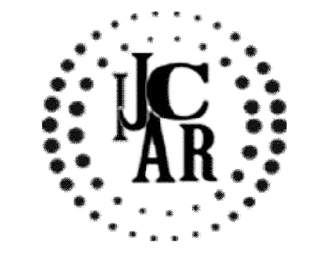

Research Article

\title{
PSYCHIATRIC MORBIDITY IN DERMATOLOGICAL PATIENTS IN RURAL SETTING
}

\author{
Kapoor $A^{1}{ }^{1}$, Gupta $V^{2}$., Ganjoo $S^{3}$., Mahla VP4 and Rai $R^{5}$ \\ 1,4,5 Department of Psychiatry, SGT Medical College and Hospital \\ 2,3 Department of Dermatology, SGT Medical College and Hospital
}

\section{A R R T I C L E I N F O}

\section{Article History:}

Received $15^{\text {th }}$ January, 2017

Received in revised form $26^{\text {th }}$ February, 2017

Accepted $22^{\text {nd }}$ March, 2017

Published online $28^{\text {th }}$ April, 2017

Key words:

Depression, Anxiety, dermatology, psychiatric

\begin{abstract}
A B S T R A C T
Back ground: Dermatological disorders lead to multiple psychological impacts on patient. There is insufficient data in this area. Objectives: To assess the prevalence of anxiety and depression among skin patients in rural setting. Patients and methods: Study was conducted in outpatient department of dermatology, Shree Guru Gobind Singh Tricentenary (SGT) Medical College and Hospital, Gurugram and 1200 patients were assessed. Hamilton Depression Rating Scale \& Hamilton Anxiety Rating Scale in Hindi version were used for assessment after taking informed consent, as these scales were designed specifically for use in non-psychiatric hospital departments. Results: Among 1200 patients taken in study, $52.83 \%$ were males and $47.17 \%$ were females, with a majority in the age range of $16-30$ years. Total $22.33 \%$ patients had mild depression, $5.92 \%$ had moderate depression, $14.5 \%$ had mild anxiety and $4.42 \%$ had moderate anxiety. None patient had found in severe depression and anxiety episode. Higher numbers of patients were associated with conditions like acne vulgaris, vitiligo, psoriasis, eczema, alopecia and all tending to be extensive, chronic and disfiguring and easily visible. Conclusion: There is a high rate of psychological disorder in dermatological patients which need to be assessed at time of treatment.
\end{abstract}

Copyright $\bigcirc 2017$ Kapoor $\boldsymbol{A}$ et al. This is an open access article distributed under the Creative Commons Attribution License, which permits unrestricted use, distribution, and reproduction in any medium, provided the original work is properly cited.

\section{INTRODUCTION}

Skin is the important organ of the body and helps in determining the external appearance of human being. It plays essential role in social and sexual communication. A person with healthy normal skin feels more confident in society ${ }^{1}$. Psychiatric disorder and psycho-social impairments are reported in various dermatological disorder. ${ }^{2}$ It has been reported that around thirty percent of the dermatological patients may have underline psychiatric disorders. ${ }^{3}$ Anxiety and depression are commonly observed in dermatological patients and their recognition is important in the management of the disease. 4

It has been noticed that patients in rural population have less awareness of dermatological problems and this leads to stigma and poor quality of life. ${ }^{5}$ Dermatologic disorder account for $15-20 \%$ of visits to general $\mathrm{OPD}^{6}$ and in lot of these patients, psychiatric disorders go undetected. Even dermatologists have noticed the need for psychiatric assessment in patient with chronic intractable dermatologic conditions, such as eczema, vitiligo, and psoriasis. ${ }^{7}, 8$ Regardless of psychiatric comorbidity, skin diseases can greatly affect patient's life. ${ }^{9}$ The various drugs used in the treatment of dermatological diseases such as steroids and

*Corresponding author: Kapoor A

Department of Psychiatry, SGT Medical College and Hospital retinoids may lead to psychiatric symptoms. ${ }^{10}$ With this background, this study has been designed specifically to assess the prevalence of depression and anxiety disorder in patients with dermatological disorders among the rural population in the catchment area of SGT Medical College and Hospital, Gurugram.

\section{Subjects and Methods}

This study was conducted in the Department of Dermatology in SGT Medical College and Hospital. This was a crosssectional study conducted from Oct 2016 to January 2017 and all patients aged above 16 years were included in the study. Total 1200 treatment naïve patients were taken for the studies that were willing to give consent. All of them were hailing from a rural background and we considered only those patients who did not suffer from any major stressful life events in the past 2 months. Patients were assessed with Hamilton Depression Rating Scale (HDRS) ${ }^{11}$ and Hamilton Anxiety Rating Scale (HARS) ${ }^{12}$. A research assistant was there to provide information and assistance in answering the questionnaire. Psychiatric evaluation was referred to an individual whose scores indicate that they were in need of more detailed psychiatric assessment, as such scores indicate the presence of clinically significant levels of anxiety and/or depression. Scores of less or equal than 7 on the HDRS scale tend to be reported by individuals with no clinically significant problems with depression. Score between 8 to 13 
indicate mild depression, 14 to 18 indicates moderate depression, more than 19 indicate severe depression. Score less than 16 on HARS scale tends to be reported by individuals with no clinically significant problem. Scoreless than 17 indicates mild severity, 18-24 mild to moderate severity and 25-30 moderate to severe. All the relevant details regarding history, examination and treatment were recorded on a pre-designed proforma.

\section{RESULTS}

Total 1200 patients were included in study and majority of the study population was between 16 to 30 years of age. Male $(52.83 \%)$ were predominated as compared to females (47.17\%). Among the males $48.42 \%$ were married and rests were single or divorcee. $54.42 \%$ females were single and rests were married or divorcee. Majority of males were employed as compared to the females. $72.56 \%$ of the males were literate as compared to females in which literacy rate was $58.13 \%$. The distribution of study population by socio-demographic characteristics is shown in table 1 .

\begin{tabular}{cccc}
\hline \multicolumn{4}{c}{ Demographic profile of patients } \\
\hline \multirow{3}{*}{ Age } & $16-30$ & Male $(\mathrm{N}=634)$ & Female(N=566) \\
& $31-45$ & $268(42.27 \%)$ & $305(53.89 \%)$ \\
& $46-60$ & $172(27.12 \%)$ & $131(23.14 \%)$ \\
Marital status & $>60$ & $121(19.09 \%)$ & $80(14.13 \%)$ \\
& Single & $73(11.51 \%)$ & $50(8.83 \%)$ \\
Occupation & Married & $307(48.42 \%)$ & $232(40.99 \%)$ \\
& Divorce/Separated & $48(7.57 \%)$ & $26(4.59 \%)$ \\
Education & Employed & $493(77.76 \%)$ & $239(42.23 \%)$ \\
status & Unemployed/Housewife & $141(22.23 \%)$ & $327(57.77 \%)$ \\
& Educated & $460(72.56 \%)$ & $329(58.13 \%)$ \\
& Illiterate & $174(27.44 \%)$ & $237(41.87 \%)$ \\
\hline
\end{tabular}

In dermatological diagnosis, acne vulgaris (23.25\%), eczema $(17.16 \%)$ and fungal infections $(15.75 \%)$ were among most common diagnosis seen in study. Male mainly presented with diagnosis of fungal infection (17.50\%), acne vulgaris $(17.35 \%)$, alopecia $(10.72 \%)$ malesma $(8.99 \%)$, as compared to females who came with more diagnosis of acne vulgaris $(29.86 \%)$, eczema $(21.20 \%)$, vitiligo $(9.36 \%)$ and scabies $(4.41 \%)$. Detail of dermatological diagnosis has been mentioned in table 2 .

Table 2 Dermatological diagnosis

\begin{tabular}{|c|c|c|c|c|}
\hline S.N & Diagnosis & $\begin{array}{c}\text { No of patients } \\
1200(\%)\end{array}$ & Male $(N=634)$ & $\begin{array}{l}\text { Female } \\
(\mathrm{N}=566)\end{array}$ \\
\hline 1 & Acne Vulgaris & $279(23.25 \%)$ & $110(17.35 \%)$ & $169(29.86 \%)$ \\
\hline 2 & Eczema & $206(17.16 \%)$ & $86(13.56 \%)$ & $120(21.20 \%)$ \\
\hline 3 & Fungal Infection & $189(15.75 \%)$ & $111(17.50 \%)$ & $78(13.78 \%)$ \\
\hline 4 & $\begin{array}{c}\text { Seborrhoeic } \\
\text { dermatitis }\end{array}$ & $108(9.0 \%)$ & $50(7.89 \%)$ & $58(10.25 \%)$ \\
\hline 5 & Scabies & $98(8.16 \%)$ & $45(7.10 \%)$ & $53(9.36 \%)$ \\
\hline 6 & Malasma & $95(7.2 \%)$ & $57(8.99 \%)$ & $38(6.71 \%)$ \\
\hline 7 & Alopecia & $49(5.75 \%)$ & $44(6.94 \%)$ & $5(0.88 \%)$ \\
\hline 8 & Herpes zoster & $28(2.33 \%)$ & $26(4.10 \%)$ & $2(0.35 \%)$ \\
\hline 9 & Psoriasis & $27(2.25 \%)$ & $14(2.20 \%)$ & $13(2.30 \%)$ \\
\hline 10 & Leprosy & $25(2.08 \%)$ & $20(3.15 \%)$ & $5(0.88 \%)$ \\
\hline 11 & Lichen planus & $23(1.92 \%)$ & $13(2.05 \%)$ & $10(1.76 \%)$ \\
\hline 12 & Vitiligo & $20(1.66 \%)$ & $15(2.36 \%)$ & $5(0.88 \%)$ \\
\hline 13 & Genital wart & $19(1.58 \%)$ & $19(2.99 \%)$ & $0(0.0 \%)$ \\
\hline 14 & Keloid & $15(1.25 \%)$ & $10(15.77 \%)$ & $5(0.88 \%)$ \\
\hline 15 & Candidiasis & $10(0.83 \%)$ & $9(1.42 \%)$ & $1(0.17 \%)$ \\
\hline 16 & Syphilis & $9(0.75 \%)$ & $5(0.79 \%)$ & $4(0.71 \%)$ \\
\hline
\end{tabular}

Mild case of depression and anxiety were found in the total sample by applying the recommended cut off values. Details of HDRS and HADS findings are shown in table 3. Total $22.33 \%$ patients had mild depression, $5.92 \%$ had moderate depression, $14.5 \%$ had mild anxiety and $4.42 \%$ had moderate anxiety. None of patients had been found in severe depression and anxiety episode.

In different sex, male showed more mild depressive symptoms in vitiligo $(62.5 \%)$, fungal infection $(52.08 \%)$, alopecia $(57.89 \%)$, herpes zoster $(70.0 \%)$, leprosy $(57.14 \%)$ as compared to female who showed mild depressive symptoms mainly in acne vulagris $(50.0 \%)$, eczema $(50.0 \%)$ and psoriasis $(50.0 \%)$. Details of severity of depression and anxiety in male and female is shown in table 4.

\section{DISCUSSION}

In our study population, during the study period, more male $(n=634)$ attended the OPD than females $(n=566)$. (Table 1$)$ A similar pattern male to female proportion was found in the study by Kar et al., ${ }^{13}$ in South India. The more female patient proportion was found in the study conducted by Kuruvilla et al ${ }^{14}$ in a Tertiary Care Centre. In our study, the most common diagnosis was acne $(23.25 \%)$, followed by eczema $(17.16 \%)$ and fungal infection (15.75\%).(Table 2) This finding was similar to the finding in a study conducted in a medical college setting in north India by Agarwal et al., ${ }^{15}$ in which eczema and acne were the most common non-infective skin diseases.

In current study, we have made our attempt to find the correlation between depression, anxiety and dermatological disorder in rural set up. An international multicentre observational cross-sectional study found that patients with psoriasis, atopic dermatitis, hand eczema and leg ulcers had the highest prevalence of depression and anxiety among dermatology patients. ${ }^{16}$ Although in our study population, (Table 3) depressive symptoms were seen in $28.25 \%$ of patients, most of them had mild depressive symptoms $(22.3 \%)$. Kim et al., ${ }^{17}$ in his study found that nearly $62.5 \%$ of the patients with skin diseases had clinical depression. This difference in the findings could be due to the varying socio-demographic profile of the study population. In current study, depressive and anxiety symptoms were mainly seen in patients with acne vulgaris, eczema, fungal infection, seborrhoeic dermatitis, scabies and malasma. Similar finding were seen in a south Indian study where depressive symptoms were mainly seen in patients with acne vulgaris, eczema, psoriasis, dermatitis and vitiligo. ${ }^{18}$

On assessing the severity of depression, we found that the moderate depression was more among the patients with alopecia, leprosy, keloid and vitiligo. Our findings were in accordance with the study conducted by Alshahwan $\mathrm{MA}^{19}$ in which the score of depression was more in patients with alopecia and against the finding of Gupta and Gupta ${ }^{20}$ in which patients with psoriasis had severe depressive symptoms. No severe episode of depression and anxiety was seen in our study. This finding was against the previous studies in which severe depression was seen among dermatology patients ${ }^{21}$. With regard of the variables associated in presence study we can conclude that psychiatric disorders are very common in dermatology patients. Their good knowledge and awareness of psychiatric diseases can help dermatologist to give a holistic care to the patients. 
Table 3 Depression and anxiety in Dermatology patients

\begin{tabular}{cccccccc}
\hline S.N & Diagnosis & Number of & \multicolumn{3}{c}{ Depression Disorder } & \multicolumn{2}{c}{ Anxiety Disorder } \\
\cline { 5 - 7 } & & & None (\%) & Mild (\%) & Mod(\%) & Mild (\%) & Mod (\%) \\
\hline 1 & Acne Vulgaris & 279 & $161(57.71)$ & $60(21.51)$ & $20(7.17)$ & $25(8.96)$ & $13(4.66)$ \\
2 & Eczema & 206 & $126(61.17)$ & $40(19.42)$ & $10(4.85)$ & $25(12.14)$ & $5(2.43)$ \\
3 & Fungal Infection & 189 & $82(43.39)$ & $39(20.76)$ & $9(4.76)$ & $38(20.11)$ & $21(11.11)$ \\
& Seborrhoeic & 108 & $49(45.37)$ & $24(22.22)$ & $5(4.63)$ & $28(25.93)$ & $2(1.85)$ \\
4 & dermatitis & & $56(57.14)$ & $23(23.46)$ & $2(2.04)$ & $15(15.31)$ & $2(2.04)$ \\
5 & Scabies & 98 & $53(55.79)$ & $25(26.32)$ & $4(4.21)$ & $11(11.58)$ & $2(2.11)$ \\
6 & Malasma & 95 & $20(40.82)$ & $12(24.49)$ & $7(14.29)$ & $10(20.41)$ & $0(0.0)$ \\
7 & Alopecia & 49 & $14(50.0)$ & $8(28.57)$ & $2(7.14)$ & $3(10.71)$ & $1(3.57)$ \\
8 & Herpes zoster & 28 & $17(62.96)$ & $5(18.52)$ & $1(3.73)$ & $3(1.11)$ & $1(3.73)$ \\
9 & Psoriasis & 27 & $14(56.0)$ & $5(20.0)$ & $2(8.0)$ & $3(12.0)$ & $1(4.0)$ \\
10 & Leprosy & 25 & $10(43.48)$ & $8(34.78)$ & $1(4.34)$ & $2(8.69)$ & $2(8.69)$ \\
11 & Lichen planus & 23 & $8(40.0)$ & $5(25.0)$ & $3(15.0)$ & $3(15.0)$ & $1(5.0)$ \\
12 & Vitiligo & 20 & $9(47.37)$ & $5(26.32)$ & $1(5.26)$ & $3(15.79)$ & $1(5.26)$ \\
13 & Genital wart & 19 & $5(33.33)$ & $4(26.67)$ & $3(20.0)$ & $2(13.33)$ & $1(6.67)$ \\
14 & Keloid & 15 & $6(60.0)$ & $2(20.0)$ & $1(10.0)$ & $1(10.0)$ & $0(0.0)$ \\
15 & Candidiasis & 10 & $4(44.44)$ & $3(33.33)$ & $0(0.0)$ & $2(22.22)$ & $0(0.0)$ \\
16 & Syphilis & 9 & $634(52.83 \%)$ & $268(22.33 \%)$ & $71(5.92 \%)$ & $174(14.5 \%)$ & $53(4.42 \%)$ \\
\hline & Total & 1200 & & & &
\end{tabular}

Table 4 Depression and anxiety in male and female

\begin{tabular}{|c|c|c|c|c|c|c|c|c|c|c|c|}
\hline \multirow[t]{3}{*}{ S.N } & \multirow[t]{3}{*}{ Diagnosis } & \multicolumn{5}{|c|}{ Depression } & \multicolumn{5}{|c|}{ Anxiety Disorder } \\
\hline & & \multirow[b]{2}{*}{ Total } & \multicolumn{2}{|c|}{ Male } & \multicolumn{2}{|c|}{ Female } & \multirow[b]{2}{*}{ Total } & \multicolumn{2}{|c|}{ Male } & \multicolumn{2}{|c|}{ Female } \\
\hline & & & Mild (\%) & Mod (\%) & Mild (\%) & Mod (\%) & & Mild (\%) & Mod (\%) & Mild (\%) & Mod (\%) \\
\hline 1 & Acne Vulgaris & 80 & $20(25.00 \%)$ & $5(6.25 \%)$ & $\begin{array}{c}40 \\
(50.00 \%)\end{array}$ & $\begin{array}{c}15 \\
(18.75 \%)\end{array}$ & 38 & $10(26.31 \%)$ & $5(13.16 \%)$ & $15(39.47 \%)$ & $8(21.06 \%)$ \\
\hline 2 & Eczema & 50 & $15(30.00 \%)$ & $3(6.00 \%)$ & $25(50.00 \%)$ & $7(14.00 \%)$ & 30 & $6(20.00 \%)$ & $2(6.67 \%)$ & $19(63.33 \%)$ & $3(10.00 \%)$ \\
\hline 3 & Fungal Infection & 48 & $25(52.08 \%)$ & $5(10.42 \%)$ & $14(29.17 \%)$ & $4(8.33 \%)$ & 59 & $29(49.15 \%)$ & $13(22.03 \%)$ & $9(15.25 \%)$ & $8(13.56 \%)$ \\
\hline 4 & Seborrhoeic dermatitis & 29 & $12(41.38 \%)$ & $2(6.90 \%)$ & $12(41.38 \%)$ & $3(10.34 \%)$ & 30 & $13(43.33 \%)$ & $1(3.33 \%)$ & $15(50.00 \%)$ & $1(3.33 \%)$ \\
\hline 5 & Scabies & 25 & $8(32.00 \%)$ & $2(8.00 \%)$ & $12(48.00 \%)$ & $3(12.00 \%)$ & 17 & $10(58.82 \%)$ & $1(5.89 \%)$ & $529.41(\%)$ & $1(5.89 \%)$ \\
\hline 6 & Malasma & 29 & $10(34.83 \%)$ & $1(3.45 \%)$ & $15(51.72 \%)$ & $3(10.34 \%)$ & 13 & $4(30.77 \%)$ & $1(7.69 \%)$ & $7(53.85 \%)$ & $1(7.69 \%)$ \\
\hline 7 & Alopecia & 19 & $11(57.89 \%)$ & $3(15.79 \%)$ & $3(15.79 \%)$ & $2(10.52 \%)$ & 10 & $10(100 \%)$ & $0(0.0 \%)$ & $0(0.0 \%)$ & $0(0.0 \%)$ \\
\hline 8 & Herpes zoster & 10 & $7(70.0 \%)$ & $1(10.0 \%)$ & $1(10.0 \%)$ & $1(10.0 \%)$ & 4 & $3(75.0 \%)$ & $1(25.0 \%)$ & $0(0.0 \%)$ & $0(0.0 \%)$ \\
\hline 9 & Psoriasis & 6 & $2(33.33 \%)$ & $0(0.0 \%)$ & $3(50.0 \%)$ & $1(16.66 \%)$ & 4 & $1(25.0 \%)$ & $0(0.0 \%)$ & $0(0.0 \%$ & $1(25.0 \%)$ \\
\hline 10 & Leprosy & 7 & $4(57.14 \%)$ & $1(14.29 \%)$ & $1(14.29 \%)$ & $1(14.29 \%)$ & 4 & $2(50.0 \%)$ & $1(25.0 \%)$ & $1(25.0 \%)$ & 0 \\
\hline 11 & Lichen planus & 9 & $4(44.44 \%)$ & $1(11.11 \%)$ & $4(44.44 \%)$ & $0(0.0 \%)$ & 4 & $1(25.0 \%)$ & $1(25.0 \%)$ & $1(25.0 \%)$ & $1(25.0 \%)$ \\
\hline 12 & Vitiligo & 8 & $5(62.5 \%)$ & $1(12.5 \%)$ & $1(12.5 \%)$ & $1(12.5 \%)$ & 4 & $1(25.0 \%)$ & 0 & $2(50.0 \%)$ & $1(25.0 \%)$ \\
\hline 13 & Genital wart & 6 & $4(66.67 \%)$ & $1(16.67 \%)$ & $1(16.67 \%)$ & 0 & 4 & $3(75.0 \%)$ & $1(25.0 \%)$ & 0 & 0 \\
\hline 14 & Keloid & 7 & $3(42.86 \%)$ & $3(42.86 \%)$ & $1(14.26 \%)$ & 0 & 3 & $1(33.33 \%)$ & $1(33.33 \%)$ & $1(33.33 \%)$ & 0 \\
\hline 15 & Candidiasis & 3 & $2(66.67 \%)$ & $1(33.33 \%)$ & 0 & 0 & 1 & $1(100.0 \%)$ & 0 & 0 & 0 \\
\hline \multirow[t]{2}{*}{16} & Syphilis & 3 & $2(66.67 \%)$ & 0 & $1(33.33 \%)$ & 0 & 2 & $2(100.0 \%)$ & 0 & 0 & 0 \\
\hline & Total & 339 & 134 & 30 & 134 & 41 & 227 & 97 & 28 & 77 & 25 \\
\hline
\end{tabular}

\section{Limitations}

1. Patients with age group $<15$ years of age were not considered

2. Since the study was focused only on rural population, the findings cannot be generalized

3. Socio-demographic details of the patients such as age group, occupation and literacy were not considered which effect the treatment requirement

4. Co morbid medical conditions such as diabetes and hypertension were not considered.

\section{Reference}

1. Aktan S, Ozmen E, Sanli B. Psychiatric disorders in patients attending a dermatology outpatient clinic. Dermatology 1998; 197: 230-4.

2. Gupta MA, Gupta AK. Psychiatric and psychological comorbidity in patients with dermatological disorders. Am J Clin Dermatol 2003; 4: 833-42.

3. Jafferany M. Psychodermatology: A guide to understanding common psychocutaneous disorders. Prim Care Companion J Clin Psychiatry. 2007; 9:20313.
4. Balieva F, Lien L, Kupfer J, Halvorsen JA, Dalgard F. Are common skin diseases among Norwegian dermatological outpatients associated with psychological problems compared with controls? An observational study. Acta Derm Venereol.2016; 96:227-31.

5. Julian CG. Dermatology in general practice. $\mathrm{Br} J$ Dermatol 1999; 141:518-20.

6. Morgan VA. Skin disease in general practice. Australas J Dermatol 1992; 33:113-5.

7. Cotterill JA. Dermatologic nondisease. Dermatol Clin 1996; 14:439-45.

8. Cotterill JA. Body dysmorphic disorder. Dermatol Clin 1996; 14:457-63.

9. Finlay AY. Quality of life assessments in dermatology. Semin Cutan Med Surg 1998; 17:291-6.

10. Koo J, Lee CS. Psycotropic agents. In: Koo J, editor. Comprehensive Dermatologic Drug Therapy. $1^{\text {st }}$ ed. Philadelphia: WB. Saunders Company; 2001. p. 40222.

11. Hamilton M. Hamilton Depression Rating Scale; A rating scale for depression. J Neurol Neurosurgery Psychiatry 1960; 23: 56-62. 
12. Hamilton M. Hamilton Anxiety Rating Scale; The assessment of anxiety states by rating. Br J Psychology 1995; 32: 50-55.

13. Kar C, Das S, Roy AK. Pattern of skin diseases in a tertiary institution in Kolkata. Indian $J$ Dermatol 2014;59:209

14. Kuruvilla M, Sridhar KS, Kumar P, Rao GS. Pattern of skin diseases in Bantwal Taluq, Dakshina Kannada. Indian J Dermatol Venereol Leprol 2000; 66:247-8.

15. Agarwal S, Sharma P, Gupta S, Ojha A. Pattern of skin diseases in Kumaun region of Uttarakhand. Indian $J$ Dermatol Venereol Leprol 2011;77:603-4

16. Dalgard FJ, Gieler U, Tomas-Aragones L, Lien L, Poot $\mathrm{F}$, Jemec GB, et al. The psychological burden of skin diseases: A cross-sectional multicenter study among dermatological out-patients in 13 European countries. $J$ Invest Dermatol.
17. Kim EK, Kim HO, Park YM, Park CJ, Yu DS, Lee JY. Prevalence and risk factors of depression in geriatric patients with dermatological diseases. Ann Dermatol $2013 ; 25: 278-84$.

18. Kim EK, Kim HO, Park YM, Park CJ, Yu DS, Lee JY. Prevalence and risk factors of depression in geriatric patients with dermatological diseases. Ann Dermatol 2013; 25:278-84.

19. AlShahwan MA. The prevalence of anxiety and depression in Arab dermatology patients. J Cutan Med Surg. 2015; 19:297-303.

20. Gupta MA, Gupta AK. Depression and suicidal ideation in dermatology patients with acne, alopecia areata, atopic dermatitis and psoriasis. $\mathrm{Br} J$ Dermatol 1998;139:846-50

21. Robina Aslam, Altaf Qadir, Faria Asad. Psychiatric morbidity in dermatological outpatients: an issue to be recognized. Journal of Pakistan Association of Dermatologists 2007; 17: 235-23.

\section{How to cite this article:}

Kapoor A et al (2017) ' Psychiatric Morbidity In Dermatological Patients In Rural Setting', International Journal of Current Advanced Research, 06(04), pp. 3110-3113.

DOI: http://dx.doi.org/10.24327/ijcar.2017.3110.0196 